\title{
Thoughts on urbanization models from a global perspective
}

\author{
Baoxing Qiu
}

\author{
Correspondence: \\ chenyong@mail.cin.gov.cn \\ General Office, Ministry of Housing \\ and Urban-rural Development, 9 \\ Sanlihe Road, Beijing 100835, \\ People's Republic of China
}

\begin{abstract}
From a global perspective, given global resource and environmental constraints, China should adhere to the Scientific Outlook on Development when choosing its model for urbanization. This article first reviews the problems with model A, represented by the USA, and model B, represented by developing countries in Latin America and Africa. It then discusses the overall planning and considerations of a new model $C$ relevant to China. Finally, it discusses measures and plans to pursue the harmonious development of eco-civilization and other civilizations under model A in China.

Keywords: Urbanization; Model C; Global perspective
\end{abstract}

Given global resource and environmental constraints, China's urbanization cannot and should not employ the development model represented by the USA, or model A as it is called, or the model of stagnation without any development, known as model B. China should instead adhere to the Scientific Outlook on Development as an urbanization model, and we shall call this model C.

Each country has only one chance for urbanization because once the process of urbanization has been completed and the layout of cities and major infrastructure fixed, it becomes extremely difficult to make substantial changes. A report from the United Nations states that although cities cover only $2 \%$ of the total area of land in the world, they consume $75 \%$ of global resources and produce an even larger proportion of global waste. Because of this, Wally N'Dow, former United Nations assistant secretary-general, said that urbanization could either be the prospect of an unparalleled brilliant future or the omen of an unprecedented catastrophe. What shape the future will take depends on what people do today.

\section{Model A with high consumption and model B with 'degrowth'}

Brown (2006), president of the United States Earth Policy Institute and an ecological economist, believes that there are two types of urbanization and economic development models, model A and model B. The former is the development model of developed countries represented by the USA. Its main characteristics include low-density spreading of cities, motorization led by private cars, fossil-fuel-based life, and overuse of disposable products. The result of such a model is that the population of the USA, which makes up only $5 \%$ of the world's population, consumes over one third of the

(c) 2014 Qiu; licensee Springer. This is an Open Access article distributed under the terms of the Creative Commons Attribution License (http://creativecommons.org/licenses/by/2.0), which permits unrestricted use, distribution, and reproduction in any medium, provided the original work is properly cited. 
world's energy. Model A is undoubtedly one of the main causes of the 'three global highs,' i.e., high oil prices, high emissions, and high food prices.

Thus, Brown (2006) proposes model B and warns that China's urbanization should never follow model A. Additionally, French scholars (Latouche 2010) proposed the 'degrowth project'. Their theory holds that growth for growth's sake causes great pressure to the limits that the biosphere can bear and that such growth is thus not sustainable. Ecological crises, particularly the greenhouse effect, will continue to deteriorate to an extent where degrowth, which reduces the size of the world economy, becomes necessary and worthy. The goal of their theory is to replace our present society of growth with a society of degrowth. The basic measures include reducing the scale of material production to the level of the 1960s and 1970s, promoting small-scale agricultural production, and reducing energy consumption. Latouche et al. (2010) emphasize repeatedly that, as long as the burden of assets and population can be reduced while retaining balance between society and the environment's systems of supporting life, human society will be able to maintain 'prosperity' within the process of turnaround and decline.

As Cook (1976) foresees in his book Man, Energy and Society, human society will 'return to a low-energy status' in three steps. The first is an entrenchment stage to reduce waste and luxury and improve the effective utilization of transport and buildings. The second step is to shut down some factories, reduce service items, replace traditional fuel with dimethyl ether fuel extracted from coal, and reduce the massive use of medicine and alcohol. The features of the third step include a majority of industrial workers returning to farms and a reduced birth rate. This is model B.

It is often difficult for developing countries to resist the temptation of model A. In the early 1990s, Western countries provided a one-size-fits-all economic reform and assistance plan to Latin American countries through International Monetary Fund and the World Bank. These countries implemented the so-called Washington Consensus, which followed the ideas of model A. The main programs included loosening government regulation and control, accelerating the development of cities, cutting down social expenses, and promoting privatization. However, after more than a decade of such practices, once-prosperous Latin American economies have been on the verge of collapse on several occasions.

The degrowth project is as impractical as the idea of model B. First, it does not address how to correct greed or the desire for capital. It would undoubtedly result in a more serious imbalance of development between rich and poor countries and between rich and poor people. Providing social insurance will also become economically unviable. The size of the high-quality labor force will decrease disastrously. Thus, economic crisis will be aggravated further. This is because the source of increasingly worsening inequality is capital's ceaseless pursuit of profits. Second, these theories require that economic powers abandon their traditional monopolistic energy industry and mode of production, which bring them wealth over the long term. This would undoubtedly be as impractical as climbing a tree to catch fish. In addition, transnational enterprises exploit resources like raw materials and energy from developing countries and transfer pollutants to these countries. This would aggravate political crises and social unrest in these countries. Third, these theories ask developing countries to slow down their economic growth so as to bear the high cost of development today. Carbon 
dioxide and pollutants emitted by developed countries during their industrialization over the past several centuries is the cause of the high cost of development today. Asking developing countries today to pay the price is not only unfair but would also cause developing countries to be mired in poverty and worsen their social crises.

This is to say that the models discussed previously cannot reverse the damage to the ecological environment caused by capital's ceaseless pursuit of profits. First, by nature, capital and its movement seek to possess natural resources as means of production to the extent possible. It will exploit these ecological resources by all means and until their exhaustion. Second, it will do its best to expand the scale of production. One of the best examples of this observation is the spreading of the subprime mortgage crisis starting from the USA. Third, capital will raise labor productivity and resource occupancy to the maximum extent possible, and it will flow freely to regions where there are more profits or capital. Finally and more importantly, the malignant competition of 'survival of the fittest' will inevitably intensify in a society built on the foundation of the principle of the movement of capital.

As Chang (2002), assistant director of Development Studies at Cambridge University, described in his book Kicking Away the Ladder - Development Strategy in Historical Perspective, present developed countries that have made a fortune following model A would definitely kick away the 'ladder' that might lead developing countries to the top, namely policies and systems shaped with model A as the template, with the excuse of the scarcity of the earth's resources and energy. They hope to stop the development of developing countries in this way. In fact, globalization driven by the movement of capital has contributed to the rocketing prices of almost all strategic resources, energy and food. This situation has kicked away the ladder more effectively than model B. However, people in many developing countries believe that it is the unsustainability of resource and energy supplies that has caused the ladder to break on its own.

Obviously, if all countries on the earth, particularly major developing countries, develop following model A, not only will food, resources, and the ecological environment be overwhelmed, but transportation will be unable to support such growth as well. However, the essential point in model B or the degrowth project, lies in eliminating all the restrictions on the movement of capital with urbanization, motorization, and industrialization bringing negative results and substituting democratic movement with the selection by capital. In short, it means asking developing countries to decelerate their development in order to fix the resource exhaustion and air pollution caused by model A. Developing countries will become foils to the consolidation and enhancement of the status of Western developed countries. The low-income class is told to 'be contented in poverty and devoted to things spiritual' and to make sacrifice to the luxurious life of the rich class. This will eventually attain the goal of the 'capitalist democracy' running wild in developing countries.

\section{Model C's thinking shows overall planning and all-around consideration}

Although there is no previous example for model $\mathrm{C}$, the initial thinking about its framework can be established by summarizing the historical lessons of model A and judging the defects of model B in reality.

First, model $\mathrm{C}$ must strive to improve the living standards of the public and promote social harmony rather than pursuing profits with capital. Such ideas should be made 
the radical goal and driver of social production activities. This means that a new strategy will be adopted that will tend to be more human-oriented and uphold intergenerational equity in the organization of economic production and the distribution of social wealth. Various types of conspicuous consumption, one-off consumption, and overconsumption will be replaced by moderate consumption. The consumerist culture that has infected modern society will be guided gradually and controlled by traditional virtues of frugality and usability. The new social contract for resource utilization of 'consuming but not exhausting' will gradually balance the defects of the traditional 'buy-out, sell-off' market-trading model. A recycling economy advocating reuse will truly be established, which is practiced throughout the process of production, consumption, recycling, and renewal between the producer and the consumer.

Second, the dual aims of an ecological society and economic sustainability will eventually replace the sole aim of economic development and become a priority of governments at various levels when formulating policy. In other words, in the process of urbanization, adequate protection should be provided to nonrenewable resources with positive externalities as well as excellent traditional cultural and economic models, such as species diversity, traditional agricultural farming methods, natural geomorphologic features, historical and community features, and cultural heritage. The awareness of modern eco-civilization will be awakened extensively, accompanied by the ancient ecological outlook of "the unity of man and heaven," and there will be innovation in this area.

Third, the driving power of economic growth will shift from the traditional consumption, exporting and investment to green consumption conforming to eco-civilization, production mainly for internal demand, and investments in renewable resources, the recycling economy, ecological restoration, and environmental protection. Only when model C causes the 'energy content' and 'resource content' of per-unit GDP to drop continuously and generate powerful 'green competitiveness' can it defeat and surpass model A and model B.

Fourth, as the foundation of the ecological environment, land must be distributed fairly both to meet the needs of mankind and to maintain species diversity. Taking into account the lives of man as well as all the lives in the natural world, fair distribution of land refers not only to fairness in the possession of resources, but also fairness in sharing space for survival. The land must be the 'Mother of Fairness' as well as the 'Mother of Prosperity.'

Fifth, the use of renewable energy and integrated buildings will trigger an architectural revolution. With the ongoing development of society, buildings now account for over $50 \%$ of all the energy consumption, pollutant discharges, and greenhouse gases. All buildings, from the house, the carrier of a family, to the city, the largest manmade structure, should be planned, designed, built, operated, and renovated in accordance with the principles of coexistence with the nature, social harmony, and minimal disturbance to the ecological environment. Buildings and the city formed thereby should make full use of various renewable resources and should recycle scarce resources. The 'distributed energy source system' combines the main entity of energy consumption and that of the energy production premise into one. It will compete with the traditional centralized energy supply system. On such a basis, cities in the real sense, or even 'zero-emissions' societies, will become very popular. 
Sixth, as urbanization is pushed forward to deeper levels, development strategy will gradually transform from export-oriented development to one that includes internal consumption demand and service outsourcing. In essence, the export of resources, energy, and primary products is the assignment and transfer of national interests and rights. Given China's resource constraints, the role of a global 'service provider' based on the rapidly changing information revolution should be more suitable than the role of the 'workshop of the world.' On such basis, combined with the flourishing of eco-agriculture and flexible production system, regional balance will be advocated with respect to the supply and demand relations of agricultural products, subsidiary agricultural products, and bulk commodities so as to effectively conserve energy in transportation.

Therefore, model $\mathrm{C}$ is a new type of urbanization model that, under the premise of retaining development, makes full use of the high efficiency of the market mechanism while being able to compensate its negative effects at a low cost. This new model discards and surpasses model A and model B. It is a profound revolution in the areas of economy, politics, and society.

There are some conditions favorable to the implementation of model $\mathrm{C}$ in China. First, there are ancient ecological and cultural values of the 'unity of man and heaven' in China. Foreign research indicates that there are specific differences between the cultural backgrounds of the nations in the East and West. People in the West often focus only on certain themes, while people in the East pay more attention to background and context. This comprehensive perspective naturally brings with it a pursuit of 'cultivating oneself, bringing order to the family, governing the country and bringing peace to the world', as well as the idea of handling conflict among humans and between man and nature with altruism. This is the cultural reason why, in the present age when model A is popular around the globe, China has spontaneously proposed 'eco-civilization' and conducting China's urbanization and industrialization in a manner of harmonious coexistence with nature.

Second, China has political parties and a state governance structure that do not have their own interests. Some politicians in the West believe that, if a new energy revolution is really to occur in the world, it might very well originate in rapidly developing China. This is because in most Western countries, neither the legislative branch, which has the power to make decisions, nor the executive branch, which has the authority to execute them, can be free from the control of interest groups. In China, the Communist Party of China (CPC), the ruling party, considers issues and carries out work from the essential starting point of realizing, maintaining, and developing the interests of the people. This kind of 'detached' status enables the $\mathrm{CPC}$ truly to shoulder the responsibility of initiating and pushing forward the new energy revolution and the transformation of the model of urban development.

Third, China's special land ownership system prevents the formation of a foundation for capital to exploit natural resources.

However, model C must be a dynamic and open model for development. It must be able to absorb the various achievements and forms of eco-civilization of other nations and constantly upgrade and optimize itself.

\section{Promoting the harmonious development of eco-civilization and other civilizations}

The next 15 to 20 years will be a continuous development period for China's urbanization. Correctly selecting the path on which eco-civilization and other 
civilizations develop harmoniously is the key to whether model $\mathrm{C}$ will be practiced successfully.

First, the current public ownership system of urban and rural land should be retained and improved. Regulation and control should be strengthened in urban and rural planning to pave the way for orderly implementation of urbanization. China is now supporting the urbanization of $21 \%$ of the world's population with only $7 \%$ of the world's arable land. This means the powerful ability of capital to exploit land resources should not be underestimated during the rapid development of urbanization. Great attention must be paid to protecting and conserving farmland, and an urban development policy of 'compactness' and 'diversity' must be implemented consistently.

Second, the construction of a new socialist countryside should be pushed forward, guided by a policy of building eco-civilization, so as to promote differentiated yet coordinated urban and rural development. China must modernize its agriculture by developing energy-saving and environmentally friendly agriculture. People need to preserve and carry forward various resources, such as excellent traditional rural architecture and culture, natural and ecological farming methods, clean water and soil, and beautiful natural scenery, so as to lay the foundation for sustained urban and rural development.

Third, the problems caused by economic globalization should be avoided and new-type industrialization should be promoted so as to create a new driving force for healthy urbanization. Driven by economic globalization, competition between cities for human resources, funds, and technology has become increasingly intense. In such a situation, cities of developing countries face the danger of being marginalized. People need to develop cities on the basis of human-oriented principles and environmental considerations. Focus should be put on speeding up the development of a new type of industrialization in which human capital and information technology are combined so as to form the new driving force of urbanization. Specifically, more investment needs to be made in science and technology. Foreign scientific and technological innovation teams and overseas Chinese scientific and technological personnel should be introduced on a large scale. They should be provided with preferential and substantial employment benefits and good living and working environment so as to create conditions for a new round of development and a rise of national innovative ability.

Fourth, the application of renewable energy should be pushed forward from multiple directions. The construction of green buildings and low-carbon cities should be promoted positively so as to improve the competitiveness of cities and the nation. At the level of individual buildings, green construction projects will be promoted comprehensively. (These are buildings that possess functions of conserving energy, water, material and land, resource recycling and utilization in the complete lifecycle of a building, and excellent indoor environmental protection). At the level of the community, stress will be put on recreating the eco-civilization and attractive features of communities. At the level of urban infrastructure, pedestrian streets and green transportation will be promoted. At the level of the city or town, coordinated development of small cities and towns will be carried out in practice. Eco-cities and eco-towns will be advocated. At the regional level, eco-city alliances and effective regional planning regulation will be conducted so as to promote joint efforts in environment protection, resource sharing, joint creation of the driving force of green development, and joint infrastructure construction. In this way, various artificial structures and production and consumption 
activities will be impelled to conserve resources and reduce pollutant emissions to the maximum extent and to be combined with the use of renewable resources to the maximum extent. Thus, the vigorous development of low-carbon cities and regions will be promoted.

Fifth, historical, cultural, and natural heritage should be protected, developed, and utilized. China has magnificent mountains and rivers. There are large numbers of historical and cultural relics in cities, towns, and villages. These are not only the main carriers of the distinctive features of towns, cities, and regions but also precious assets for sustained urban and rural development. During the grand tide of urbanization, all citizens should be made more aware of these resources. Such high-level resources whose values increase constantly should be restored and protected so that the offspring of the Chinese nation can utilize these green resources in a sustainable manner.

Sixth, work should start from rationally allocating urban space. Transportation demand management should be strengthened to promote the harmonious development of urbanization and motorization. Motorization is always a 'double-edged sword' for orderly urbanization. The role of urban planning in allocating transportation resources should be brought into full play. Public transportation should be given preferential treatment. The advantage of China as an 'empire of bicycles' will continue to be exerted. A green transportation system will be established that includes motor vehicles.

Seventh, China should respond proactively to its increasingly serious water crisis. In China, the imbalance of the spatial distribution of water resources and water pollution has become increasingly aggravated. These have become major obstructions to healthy urbanization. The current urgent task is to reduce reliance on 'major interception, major discharge and major transfer' water engineering projects. A shift should be advocated from development-discharge unilateral utilization to recycling utilization, from individual water engineering projects to the overall optimization of water ecology, from simply intercepting and discharging floods to achieving harmonious coexistence with flooding water, and from overly relying on distant water transfer to solving urban water supply demand through recycling and reuse locally.

Eighth, implementation of the Scientific Outlook on Development and orderly urbanization must be based on the region as a whole when relevant work is done in centralized resource utilization planning, environment protection, industrial distribution, and major project construction. The basic method of such work is to expand planning and regulation originally limited to a city so as to cover the region where the city group involved is located. Relevant work should be done on city and town groups - the artificial structures that have the largest influence on environmental resources - so as to achieve the greatest benefits of urbanization with minimal impact on the ecological environment. Chinese Academy of Social Sciences and Tongji University. 
References

Brown L (2006) Plan B 2.0: rescuing a planet under stress and a civilization in trouble. WW Norton \& Company

Incorporated, New York, 莱斯特.R.布朗,“B模式”2.0一拯救地球, 延续文明. 第一版. 北京: 东方出版社, 2006:4

Chang HJ (2002) Kicking away the ladder-development strategy in historical perspective. Anthem Press, London, 张夏

准, 《富国陷阱—发达国家为何踢开梯子?》, 肖炼等译, 社会科学文献出版社,2007年

Cook E (1976) Man, energy, society. W.H. Freeman, San Francisco

Latouche S (2010) Degrowth. J Cleaner Production 18(6):519-522

doi:10.1186/2196-5633-2-5

Cite this article as: Qiu: Thoughts on urbanization models from a global perspective. China Finance and Economic

Review 2014 2:5.

\section{Submit your manuscript to a SpringerOpen ${ }^{\circ}$ journal and benefit from:}

- Convenient online submission

- Rigorous peer review

- Immediate publication on acceptance

- Open access: articles freely available online

- High visibility within the field

Retaining the copyright to your article

Submit your next manuscript at $\boldsymbol{\sim}$ springeropen.com 